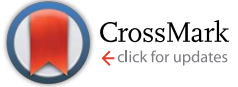

Cite this: RSC Adv., 2017, 7, 15769

Received 18th December 2016

Accepted 4th March 2017

DOI: 10.1039/c6ra28362d

rsc.li/rsc-advances

\section{An antimicrobial peptide-based colorimetric bioassay for rapid and sensitive detection of $E$. coli $0157: \mathrm{H} 7 \dagger$}

\author{
Zhaohui Qiao, ${ }^{a}$ Chunyang Lei, ${ }^{* a}$ Yingchun Fu ${ }^{a}$ and Yanbin Li*ab
}

\begin{abstract}
Rapid and sensitive detection of foodborne pathogens can effectively prevent or reduce the outbreaks of foodborne diseases. In this study, an antimicrobial peptide (AMP)-based colorimetric bioassay was developed for rapid and sensitive detection of Escherichia coli O157:H7. AMP was conjugated with horseradish peroxidase (AMP-HRP) to develop a signal reporter instead of antibody-HRP with a higher sensitivity. AMP-HRP could anchor on the surface of target bacteria rapidly through electrostatic and hydrophobic interactions. After unbound probes were removed by filtration, HRP catalyzed 3,3',5,5'tetramethylbenzidine (TMB) to colored product, which was measured using UV-vis spectroscopy to quantify E. coli O157:H7. Due to the abundant AMP-binding sites on the surface of target bacteria, the proposed bioassay could detect $E$. coli $\mathrm{O} 157: \mathrm{H} 7$ as low as $13 \mathrm{cfu} \mathrm{mL}^{-1}$ in a pure culture with a linear range of $10^{2}-10^{5} \mathrm{cfu} \mathrm{mL}^{-1}$ in $45 \mathrm{~min}$ without pre-enrichment. Combined with an immunomagnetic capture-release procedure, sensitive and selective detection of $E$. coli $0157: \mathrm{H} 7$ in food samples was achieved.
\end{abstract}

\section{Introduction}

Foodborne diseases are one of the most threatening public health problems worldwide. ${ }^{1}$ There are 9.4 million cases of foodborne illness every year in the United States caused by foodborne pathogens. ${ }^{2}$ Escherichia coli (E. coli) O157:H7 is one of the most notorious foodborne pathogens that can cause severe illness such as hemorrhagic diarrhea, vomiting or acute kidney failure. ${ }^{3,4}$ It was estimated that the infectious dose of $E$. coli $\mathrm{O} 157: \mathrm{H} 7$ may be as low as 10 to 100 cells and the infections could be lethal without proper medical treatment. ${ }^{5}$ Therefore, $E$. coli $0157: \mathrm{H} 7$ was classified as a "zero tolerance" adulterant and there is an urgent need to develop rapid and sensitive methods for the detection of $E$. coli $\mathrm{O} 157: \mathrm{H} 7$ in food safety inspection and environmental monitoring. ${ }^{6}$ The conventional culture-based methods are the golden standard methods for the detection of $E$. coli O157:H7. However, these methods are labor-intensive and time-consuming, which cannot satisfy the requirement of rapid detection. ${ }^{7}$ Currently, some rapid detection methods have been developed, including PCR-based nucleic acid amplification tests and enzyme-linked immunosorbent assay. ${ }^{\mathbf{8} 9}$ PCRbased techniques are highly sensitive and can even achieve

${ }^{a}$ College of Biosystems Engineering and Food Science, Zhejiang University, Hangzhou 310058, China.E-mail: yanbinli@zju.edu.cn; chunyangly@126.com

${ }^{b}$ Department of Biological and Agricultural Engineering, University of Arkansas, Fayetteville, Arkansas 72701, USA

$\dagger$ Electronic supplementary information (ESI) available. See DOI: $10.1039 / \mathrm{c} 6 \mathrm{ra} 28362 \mathrm{~d}$ single-cell detection, yet require the extraction of nucleic acids and are limited in portability. ${ }^{\mathbf{1 0 , 1 1}}$ The immunoassays based on antigen-antibody reaction are simple and sensitive methods for the high-throughput detection of bacteria with high specificity. ${ }^{\mathbf{1 2}}$ However, the specific antibody-antigen interactions limit the recognition sites leading to the insensitivity for measurement of bacteria at low concentrations. ${ }^{\mathbf{1 3 , 1 4}}$

AMPs are found in multiple niches in nature, providing the first line of defense against infection by acting as natural antibiotics. ${ }^{15}$ Most of antimicrobial peptides contain 12-50 amino acid residues, including two or more positively charged residues and a large proportion of hydrophobic residues. They can attach on the surface of bacteria mainly through electrostatic and hydrophobic interactions. ${ }^{16-18}$ Compared with antibodies, AMPs have advantages of stableness in harsh environment, low-cost synthesis, and easy modification. ${ }^{19-21}$ Therefore, AMPs can be used as an alternative to antibodies as the recognition elements in the detection of foodborne pathogens. Recently, several electrochemical biosensors for the detection of foodborne pathogens were developed by utilizing immobilized AMPs as capture probes. ${ }^{\mathbf{1 3 , 1 9 , 2 1 , 2 2}}$ These methods are simple and practicable, but with low sensitivity due to the lack of the processes of signal amplification. Previous studies revealed that hydrophobic residues of AMPs can attach on to the amphiphilic negatively charged lipopolysaccharide (LPS) in the bacterial membrane. ${ }^{23}$ Moreover, each $E$. coli cell contains approximately $3.5 \times 10^{6}$ LPS molecules occupying three-quarters of the bacterial surface. ${ }^{24}$ Therefore, in conjunction with proper signal reporters, AMPs can be adopted as effective signal amplifiers. 


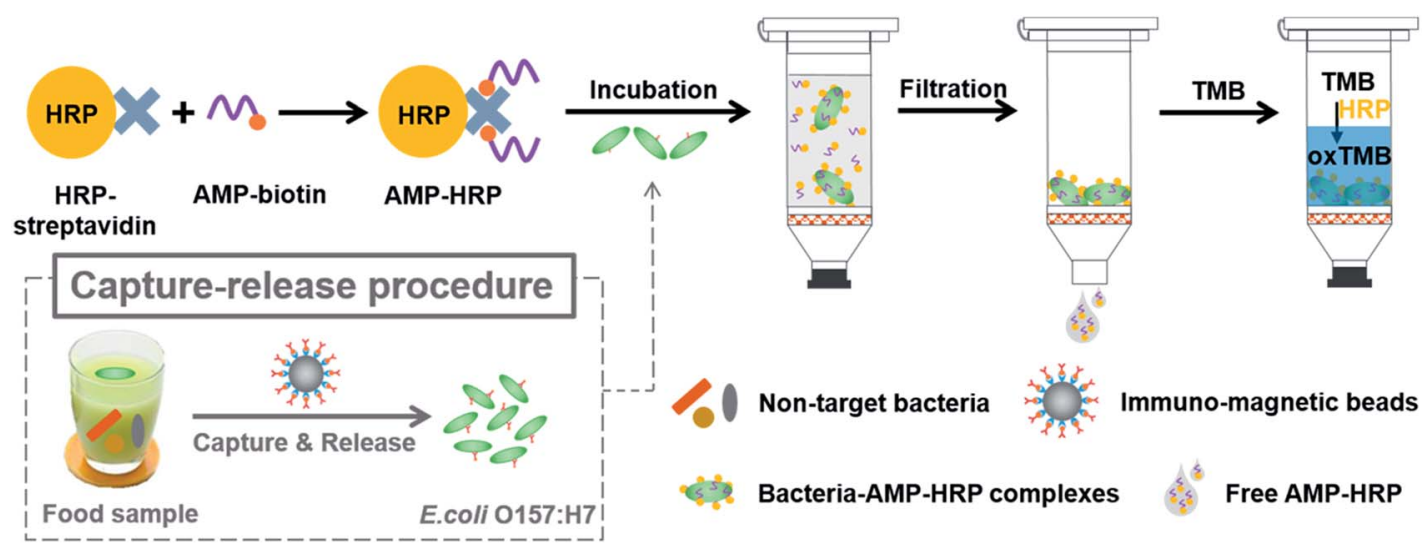

Scheme 1 Illustration of the antimicrobial peptide-based colorimetric bioassay for the detection of E. coli $\mathrm{O} 157: \mathrm{H} 7$.

Arcidiacono's group developed an immunomagnetic assay for detection of $E$. coli $\mathrm{O} 157: \mathrm{H} 7$ based on Cy5-labeled AMPs, revealing a 10-fold higher sensitivity compared with Cy5-antibody. ${ }^{25}$ However, magnetic beads inevitably reduced the binding efficiency between AMPs and cells due to the steric effects. In addition, the non-specific binding to the immunomagnetic beads resulted in high noise in background and relatively low sensitivity. Therefore, reducing or eliminating nonspecific absorption and steric effects are important to improve the sensitivity of AMPs-based detection methods.

Filtration has been proven to be effective for the rapid isolation and concentration of foodborne pathogens. ${ }^{26,27}$ Herein, combined with filtration, we developed an AMP-based colorimetric bioassay utilizing AMP-HRP as the whole cell surface binding probes for rapid and sensitive detection of $E$. coli O157:H7. Magainin I, an AMP with 23 amino acid residues, exhibiting high affinity toward E. coli $\mathrm{O} 157: \mathrm{H} 7,{ }^{13}$ was selected as the recognition element. As shown in Scheme 1, AMP-HRP conjugates were fabricated via streptavidin and biotin interaction. AMP-HRP probes can bind on the surface of bacteria rapidly with high density through the interaction between AMP and amphiphilic negatively charged LPS..$^{25}$ After that, the filter tubes were used to remove unbound probes to reduce nonspecific binding and steric effects that exist extensively in immunomagnetic assays. Subsequently, the concentration of $E$. coli $\mathrm{O} 157: \mathrm{H7}$ could be visualized and quantified by UV-vis absorption measurement after the colorimetric reaction catalyzed by AMP-HRP on the surface of target bacteria. Finally, sensitive and selective detection of $E$. coli $\mathrm{O} 157: \mathrm{H} 7$ in food samples was achieved using the proposed bioassay in combination with an immunomagnetic capture-release procedure.

\section{Experimental section}

\subsection{Materials and apparatus}

Antimicrobial peptide Magainin I (GIGKFLHSAGKGKAFVGEIMK), with a C-terminal labeled biotin, was chemically synthesized by GL Biochem Ltd. (Shanghai, China) with a purity $>85 \%$. The stock solution of AMP was prepared by the reconstitution of the lyophilized powders in phosphate buffered saline (PBS) (Sigma-
Aldrich) consisting of $154 \mathrm{mmol} \mathrm{L}^{-1} \mathrm{NaCl}$ and $10 \mathrm{mmol} \mathrm{L}^{-1}$ phosphate (pH 7.4). HRP-conjugated streptavidin and skim milk were purchased from Sangon Biotech Co. Ltd. (Shanghai, China). $3,3^{\prime}, 5,5^{\prime}$-Tetramethylbenzidine (TMB) Liquid Substrate System was from Aladdin Industrial Corporation (Shanghai, China). The Amicon Ultra-0.5 Centrifugal Filter Devices with $10 \mathrm{kDa}$ MWCO were purchased from Millipore (Billerico, MA, USA). Filter-tubes with four layers of $1 \mu \mathrm{m}$ pore size were purchased from Haimen United Laboratory Equipment Development Co., Ltd. (Haimen, China). Rabbit anti-E. coli polyclonal antibodies (4.0-5.0 $\mathrm{mg} \mathrm{mL}^{-1}$ ) were purchased from Meridian Life Science Inc. (Memphis, TN, USA). Stock bacterial cultures of E. coli O157:H7 (ATCC 43888), Vibrio parahaemolyticus (V. parahaemolyticus, ATCC 33847), Salmonella typhimurium (S. typhimurium, ATCC 14028), and Listeria monocytogenes (L. monocytogenes, ATCC 19115) were obtained from American Type Culture Collection (ATCC, Manassas, VA, USA). E. coli DH5 $\alpha$, BL21 and Staphylococcus aureus (S. aureus CMCC 26003) were from Tiangen Biotech Co., Ltd. (Beijing, China). Sorbitol MacConkey agar (SMAC), Baird Parker agar, xylose-lysine-tergitol 4 (XLT4) agar, Difco CTBS agar are purchased from BD (Becton, Dickinson and Company). PALCAM agar and LB nutrient agar were obtained from Beijing Land Bridge Technology Co., Ltd. (Beijing, China). BcMagTM monomeric avidin magnetic beads were purchased from Bioclone Inc., (San Diego, CA, USA). All aqueous solutions were prepared using freshly deionized water (18.2 $\mathrm{M} \Omega \mathrm{cm}$ specific resistivity) obtained with a Milli-Q water purification system (Millipore, Billerica, MA, USA) and sterilized by laboratory autoclave (Sanyo, Japan). The UV-vis absorption spectra were monitored using a UV-vis spectrophotometer (8453, Agilent Technologies, Santa Clara, USA) and a Synergy H1 Hybrid Multi-Mode Microplate reader (BioTek, Vinooski, VT, USA). All centrifugations were carried on a $22 \mathrm{R}$ Refrigerated Microcentrifuger (Bechman Coulter, Fyllerton, CA, USA).

\subsection{Preparation and culture of bacteria}

E. coli $\mathrm{O} 157: \mathrm{H} 7$, as well as other bacteria used as non-target cells, was prepared by growing the stock cultures in brain heart infusion (BHI) broth (BD, San Diego, CA, USA) at $37^{\circ} \mathrm{C}$ for $16-20 \mathrm{~h}$. After washed three times by centrifuging at $8000 \mathrm{rpm}$ 
for $5 \mathrm{~min}$, the bacteria solutions were 10 -fold diluted with sterile PBS to obtain the samples with different concentrations ranging from 10 to $10^{7} \mathrm{cfu} \mathrm{mL}^{-1}$. To determine the cell numbers of $E$. coli 0157:H7, S. aureus, L. monocytogenes, S. Typhimurium, V. parahaemolyticus, E. coli $\mathrm{DH} 5 \alpha$ and $E$. coli $\mathrm{BL} 21,100 \mu \mathrm{L}$ of proper dilutions were plated onto the surface of corresponding agars, i.e., Sorbitol MacConkey agar (SMAC), Baird Parker agar, PALCAM agar, xylose-lysine-tergitol 4 (XLT4) agar, CTBS agar and LB nutrient agar, respectively. After incubation at $37{ }^{\circ} \mathrm{C}$ for $24 \mathrm{~h}$ (for bacteria except L. monocytogenes) or $48 \mathrm{~h}$ (for L. monocytogenes), colonies on the plates were counted to determine the number of viable cells in terms of colony forming units per milliliter ( $\mathrm{cfu} \mathrm{mL}{ }^{-1}$ ). Finally, the obtained bacteria were killed in boiling water for $15 \mathrm{~min}$ and stored at $4{ }^{\circ} \mathrm{C}$ for further use.

\subsection{Preparation of AMP-HRP probes}

AMP-HRP conjugates were fabricated via streptavidin and biotin interaction. In a typical procedure, biotinylated AMPs (5 $\left.\mu \mathrm{mol} \mathrm{L}{ }^{-1}\right)$ were mixed with HRP-conjugated streptavidin (50 $\mu \mathrm{g}$ $\mathrm{mL}^{-1}$ ) and then the mixture was placed in a programmable rotating-mixer (Grant-bio, Grant Instruments (Cambridge) Ltd., $\mathrm{UK}$ ) at $15 \mathrm{rpm}$ for $30 \mathrm{~min}$ at room temperature (RT). The molar ratio of AMPs and HRP is $10: 1$ in order to guarantee every HRP molecule was conjugated with AMPs. After that, the mixture was transferred to Amicon® Ultra filter device (10 kDa MWCO, 0.5 $\mathrm{mL}$ ) and centrifuged at $10000 \mathrm{rpm}$ for $10 \mathrm{~min}$. To make sure unbound AMPs removed completely, the mixture was washed thrice by $0.5 \mathrm{~mL}$ of PBS and added PBS to make HRP with a final concentration of $50 \mu \mathrm{g} \mathrm{mL}{ }^{-1}$. The conjugates were prepared on the test day and stored at $4{ }^{\circ} \mathrm{C}$ for further use.

\subsection{AMP-HRP binding assay}

E. coli $\mathrm{O} 157: \mathrm{H} 7$ cells were grown and prepared in PBS as described above. One $\mathrm{mL}$ of serially diluted cells incubated with $10 \mu \mathrm{L}$ of $50 \mu \mathrm{g} \mathrm{mL}^{-1}$ AMP-HRP probes in the low binding tubes (SARSTEDT AG \& Co., Germany) on a programmable rotatingmixer at $15 \mathrm{rpm}$ for $10 \mathrm{~min}$ at RT. The same amount of AMPHRP probes was added to $1 \mathrm{~mL}$ of PBS as negative control. After incubation, the mixtures were centrifuged at $10000 \mathrm{rpm}$ for $5 \mathrm{~min}$ and washed three times by $1 \mathrm{~mL}$ of PBS. Subsequently, $100 \mu \mathrm{L}$ of TMB was added into the tube for color reaction, followed by $100 \mu \mathrm{L}$ of $2 \mathrm{~mol} \mathrm{~L}^{-1} \mathrm{H}_{2} \mathrm{SO}_{4}$ to stop the reaction $5 \mathrm{~min}$ later. Finally, the UV-vis absorption spectrum of each sample was measured by the microplate reader.

\subsection{Detection of $E$. coli $0157: \mathrm{H7}$}

E. coli $\mathrm{O} 157: \mathrm{H7}$ cells were cultured and prepared in PBS as described above. An aliquot of $800 \mu \mathrm{L}$ of serially diluted E. coli 0157:H7 were mixed with $0.36 \mu \mathrm{g} \mathrm{mL}^{-1}$ of AMP-HRP and incubated for $10 \mathrm{~min}$ in filter tubes at RT when the tubes outlets were sealed. The same amount of AMP-HRP probes was added to $800 \mu \mathrm{L}$ of PBS as negative control. After the incubation, the outlets were open and the mixtures were filtered through the membrane under centrifugation at $4000 \mathrm{rpm}$ for $1 \mathrm{~min}$. To reduce the non-specific attachment, the membrane was washed thrice by flowing $500 \mu \mathrm{L}$ PBS through the membrane. After that,
$100 \mu \mathrm{L}$ of TMB was added into the tube for color reaction, followed by adding $100 \mu \mathrm{L}$ of $2 \mathrm{~mol} \mathrm{~L}^{-1} \mathrm{H}_{2} \mathrm{SO}_{4}$ to stop the reaction 5 min later. Finally, the UV-vis absorption spectrum of each sample was measured by the microplate reader.

\subsection{Preparation of immunomagnetic beads}

The immunomagnetic beads (IMBs, magnetic beads conjugated with the antibodies) were prepared based on monomeric avidin-biotin interaction. After pretreatment according to the manufacturer's protocol, the monomeric avidin magnetic beads were immediately incubated with $500 \mu \mathrm{L}$ of biotin-conjugated antibodies $\left(0.5 \mathrm{mg} \mathrm{mL} \mathrm{mL}^{-1}\right)$ for $30 \mathrm{~min}$. After removal of the unattached antibodies in the solution, the immunomagnetic beads were washed three times and re-suspended in $500 \mu \mathrm{L}$ of PBS $\left(1 \mathrm{mg} \mathrm{mL}{ }^{-1}\right)$ and stored at $4{ }^{\circ} \mathrm{C}$ for further usage.

\subsection{Capture and release of $E$. coli $0157: \mathrm{H7}$}

IMBs were used to specifically capture $E$. coli O157:H7. Twenty $\mu \mathrm{L}$ of IMBs were first incubated with $800 \mu \mathrm{L}$ of $E$. coli $0157: \mathrm{H} 7$ with different concentrations at $15 \mathrm{rpm}$ for $45 \mathrm{~min}$ in a $1.5 \mathrm{~mL}$ sterile centrifuge tube, which was blocked by $4 \%$ BSA for $30 \mathrm{~min}$. After magnetic separation for $1 \mathrm{~min}$ and washing with $800 \mu \mathrm{L}$ of $\mathrm{H}_{2} \mathrm{O}$, E. coli $\mathrm{O} 157: \mathrm{H7}$ cells captured by IMBs were released by $100 \mu \mathrm{L}$ of elution buffer $\left(1 \mathrm{mmol} \mathrm{L}^{-1} \mathrm{HCl}\right)$ for $1 \mathrm{~min}$. After magnetic separation, the supernatant containing $E$. coli O157:H7 was neutralized by $700 \mu \mathrm{L}$ of PBS ( $\mathrm{pH} 7.4$ ) and ready for the detection using AMP-based bioassay. Meanwhile, the negative control was conducted by substituting the sample containing E. coli O157:H7 with PBS of same volume.

\subsection{Preparation of spiked food samples}

The apples and ground beef were bought from a local supermarket. The apples were washed and squeezed by the juicer (Midea, WBL1021S), the supernatant was collected and flowed through the filter paper to get rid of the impurities. Then the $\mathrm{pH}$ of the juice was adjusted to 7.4 by $1 \mathrm{~mol} \mathrm{~L}^{-1} \mathrm{NaOH}$ solution. At the same time, $25 \mathrm{~g}$ of ground beef was mixed with $225 \mathrm{~mL}$ of PBS in filter bags (Labplas Inc., Quebec, Canada) and stomached with Stomacher 400 (Seward, Norfolk, UK) for $1 \mathrm{~min}$. Then the washing solution was collected. After that, the apple juice and ground beef washing solution was spiked with $E$. coli O157:H7 at different concentration ranging from 10 to $10^{6} \mathrm{cfu}$ $\mathrm{mL}^{-1}$, respectively. Ultimately, the spiked apple juice and beef samples were used for bacteria detection based on the same procedure as that of pure culture detection. Besides, the traditional plate-counting method for assaying the bacteria in samples served as the standard method.

\section{Results and discussion}

\subsection{Binding capacity of AMP-HRP}

It was reported that conjugated with small molecules (e.g. Cy5) had no effects on the interaction between AMPs and bacteria. ${ }^{28}$ However, whether the AMP can retain its binding capacity as conjugated with biomacromolecules is still unknown. Therefore, the affinity of AMP-HRP toward E. coli O157:H7 was 
investigated by a simple centrifugation-based method. E. coli O157:H7 cells were firstly incubated with AMP-HRP probes and then unbound probes were removed by centrifugation. The AMP-HRP probes bound on the surface of bacteria were precipitated along with bacteria and catalyzed the conversion of TMB into a blue color product, which could be visualized by naked eye or quantified with spectrometer. As shown in Fig. 1, as the concentration of bacteria increased from $10^{5}$ to $10^{8} \mathrm{cfu}$ $\mathrm{mL}^{-1}$, the optical density at $450 \mathrm{~nm}\left(\mathrm{OD}_{450}\right)$ increased gradually and presented a proportional relationship with the concentrations of bacteria. These results indicated that AMP retains the binding ability against bacteria even though conjugated with HRP. However, in the presence of bacteria at low concentrations $\left(10-10^{5} \mathrm{cfu} \mathrm{mL}^{-1}\right)$, the optical densities at $450 \mathrm{~nm}$ were as low as that of negative control and the absorption spectra almost overlapped with the curve of the control. This is possibly attributed to the great loss of bacteria-AMP-HRP complexes during centrifugation and washing steps, which demonstrates that the direct centrifugation-based method is not sensitive enough for the detection of bacteria.

\subsection{Optimization of detection conditions}

To obtain the best assay performance, two parameters including the concentration of AMP-HRP probes and incubation time
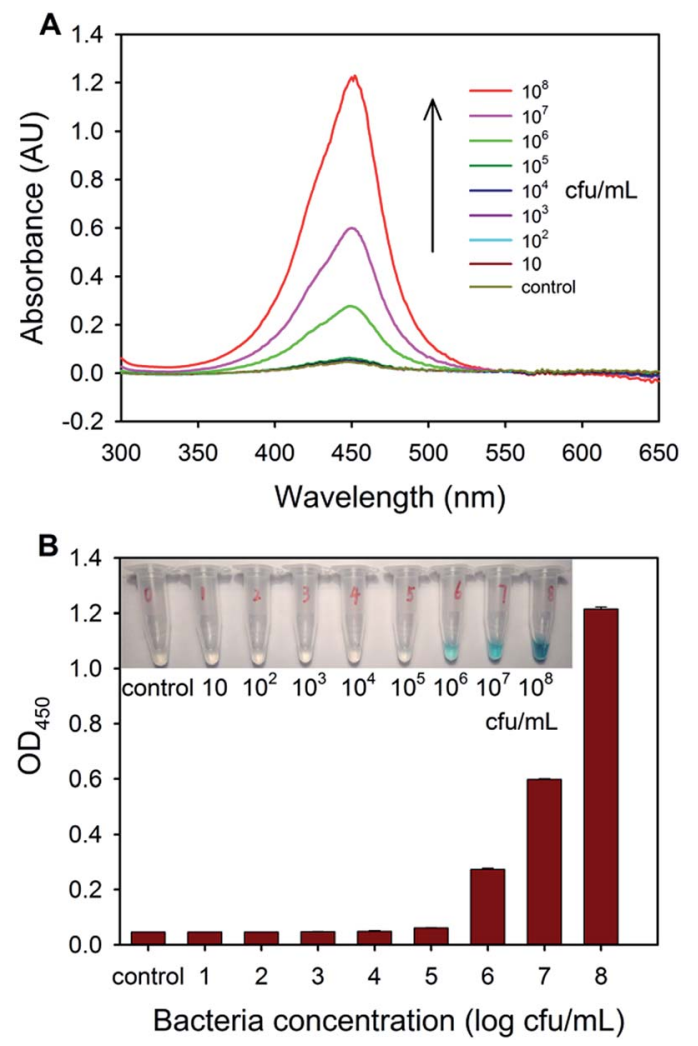

Fig. 1 (A) Absorption spectra of the samples with the concentrations

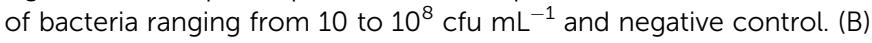
The absorbance at $450 \mathrm{~nm}$ corresponding to the curve of (A). Insert: photographic images corresponding to the bars (from left to right, negative control, $10,10^{2}, 10^{3}, 10^{4}, 10^{5}, 10^{6}, 10^{7}$ and $10^{8} \mathrm{cfu} \mathrm{mL} \mathrm{m}^{-1}$ ). between AMP-HRP and bacteria were optimized. As shown in Fig. $2 \mathrm{~A}, \mathrm{OD}_{450}$ of sample in the presence of E. coli $\mathrm{O} 157: \mathrm{H} 7\left(10^{5}\right.$ cfu $\mathrm{mL}^{-1}$, red line) increased rapidly as the concentration of AMP-HRP increased from 0.22 to $0.36 \mu \mathrm{g} \mathrm{mL}{ }^{-1}$, which indicated that AMP-HRP continuously bind on the surface of target bacteria. After that, the signal slowly reached a platform due to the saturation of probes on the surface of the target bacteria. At the meantime, the background $\left(\mathrm{OD}_{450}\right.$ of negative control, blue line) increased gradually as the concentration of AMP-HRP increased. The change in the optical signal $\left(\mathrm{OD}_{450}\right.$ of sample subtracted that of control, $\Delta \mathrm{OD}_{450}$, gray bar) was employed as the signal output of the AMP-based bioassay and the maximum value of $\Delta \mathrm{OD}_{450}$ was obtained as the concentration of AMP-HRP was $0.36 \mu \mathrm{g} \mathrm{mL}{ }^{-1}$. Therefore, $0.36 \mu \mathrm{g} \mathrm{mL} L^{-1}$ of AMP-HRP was adopted in the following experiments. Furthermore, the effect of incubation time ranging from 5 to $25 \mathrm{~min}$ on $\Delta \mathrm{OD}_{450}$ was also investigated. As shown in Fig. $2 \mathrm{~B}$, a rapid increase of $\Delta \mathrm{OD}_{450}$ was observed in the initial $10 \mathrm{~min}$, indicating that AMP-HRP quickly bind on the surface of bacteria. No significant increase was observed when the incubation was more than $10 \mathrm{~min}$, suggesting that the binding reached saturation. This result agrees with some previous reports..$^{\mathbf{8}, 29}$ Thus, $10 \mathrm{~min}$ was used as the optimal reaction time in the subsequent experiment. In addition, $\Delta \mathrm{OD}_{450}$

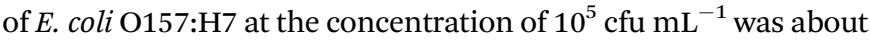
0.2 in this assay, which is 13-fold higher than that using the direct centrifugation method $\left(\Delta \mathrm{OD}_{450}=0.015\right.$, Fig. 1$)$. Therefore,
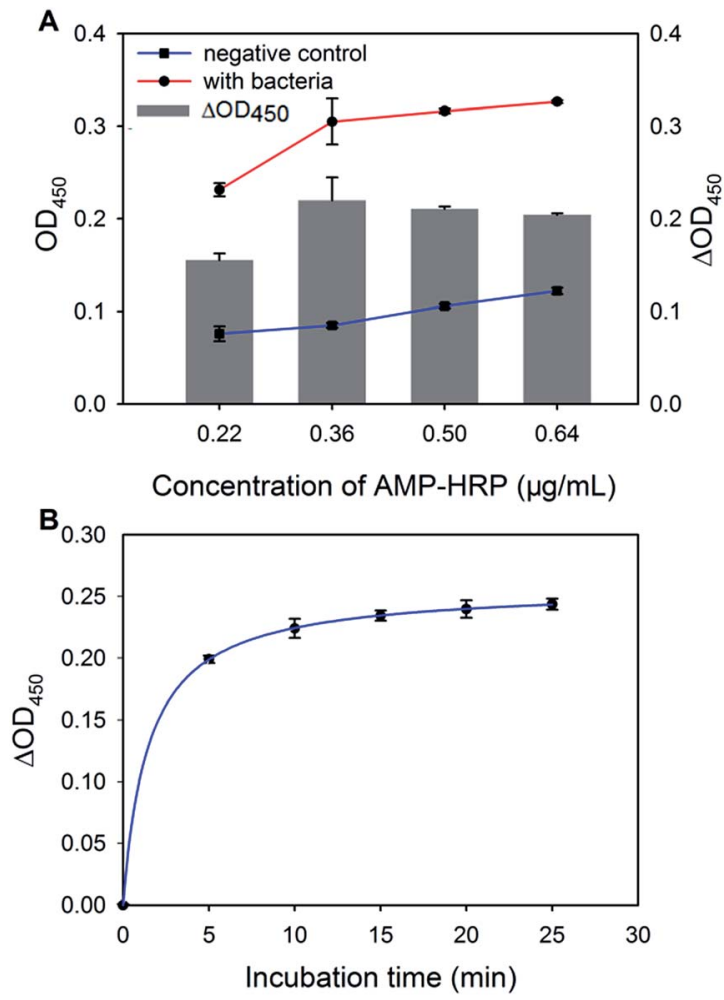

Fig. 2 (A) The influence of AMP-HRP at different concentrations on the optical signal. (B) The influence of different incubation times on the optical signal. The concentration of AMP-HRP is $0.36 \mu \mathrm{g} \mathrm{mL}^{-1}$, and the concentration of $E$. coli $\mathrm{O} 157: \mathrm{H} 7$ is $10^{5} \mathrm{cfu} \mathrm{mL}^{-1}$. Error bars represent S.D. $(n=3)$. 
the filtration-based method provides an effective method for rapid isolation and concentration of foodborne pathogens.

\subsection{Detection of $E$. coli 0157:H7}

Under the optimized conditions, the AMP-based bioassay was validated first in the presence of different concentrations of $E$. coli $\mathrm{O} 157: \mathrm{H7}$ ranging from 10 to $10^{5} \mathrm{cfu} \mathrm{mL}^{-1}$ in the pure culture. The responses were evaluated in terms of $\Delta \mathrm{OD}_{450}$, which is the difference in $\mathrm{OD}_{450}$ value between the sample with the presence of target bacteria and the negative control. As shown in the inset of Fig. 3A, the color of the solution changed gradually from light blue to dark blue when the concentration of E. coli $\mathrm{O} 157: \mathrm{H} 7$ increased from 10 to $10^{5} \mathrm{cfu} \mathrm{mL}^{-1}$. Accordingly, the value of $\Delta \mathrm{OD}_{450}$ increased linearly as the concentration of E. coli $\mathrm{O} 157: \mathrm{H} 7$ grew exponentially, and the corresponding regression equation was calculated as $y=0.052 x-0.048\left(R^{2}=0.974\right)$, where $x$ is the concentration of bacteria in $\log \mathrm{cfu} \mathrm{mL}^{-1}$ and $y$ is the value of $\Delta \mathrm{OD}_{450}$. The limit of detection (LOD), defined as the average blank value plus 3 times the value of standard deviation of the
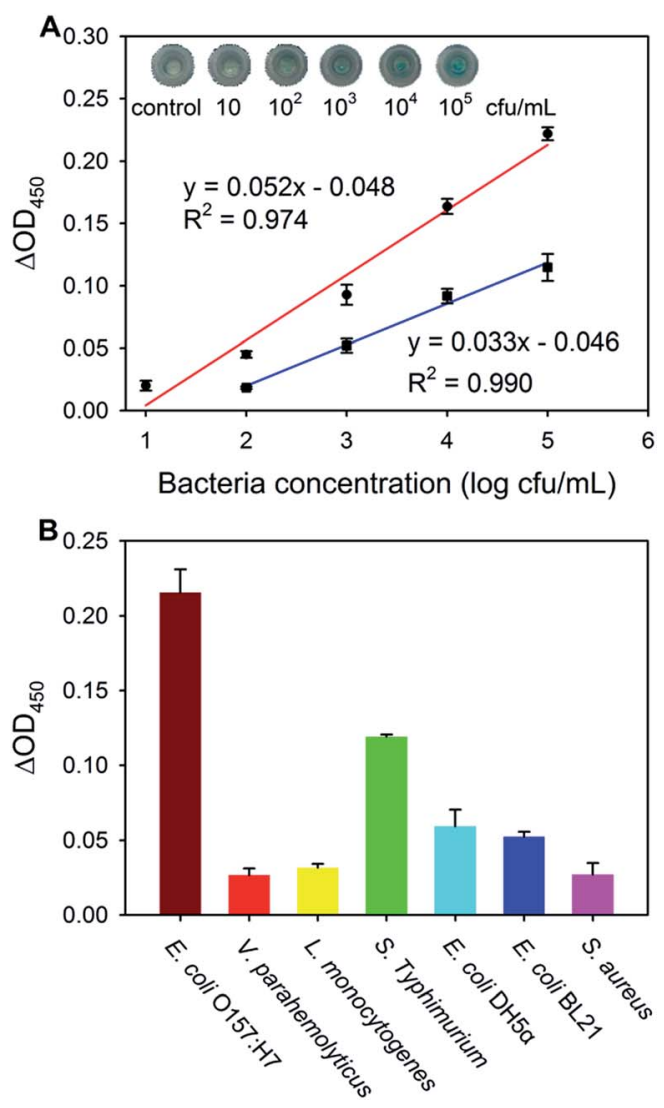

Fig. 3 (A) Detection of E. coli O157:H7 in pure culture by the AMPbased bioassay. Different concentrations of E. coli O157:H7 were detected by the AMP-based bioassay (red line) and antibody-based bioassay (blue line). Insert: photographic images corresponding to the sample of each concentration in pure culture detected by AMP-based

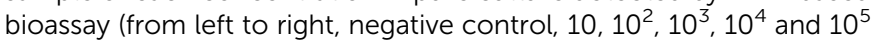
$\mathrm{cfu} \mathrm{mL}^{-1}$ ). (B) The selectivity of the proposed AMP-based bioassay toward E. coli O157: H7. The concentrations of E. coli O157: $\mathrm{H} 7$ and the non-target bacteria are $10^{5}$ and $10^{6} \mathrm{cfu} \mathrm{mL}^{-1}$, respectively. Error bars represent S.D. $(n=3)$. blank value, converted to the concentration of E. coli $\mathrm{O} 157: \mathrm{H} 7$ (ref. 30) for the proposed AMP-based bioassay was calculated to be $13 \mathrm{cfu} \mathrm{mL}^{-1}$. Besides, different concentrations of bacteria were also detected by antibody-HRP based assay (details in ESI $\dagger$ ). Apparently, the sensitivity of AMP-based bioassay was much better than that of antibody based assay (Fig. 3A, blue line). These results can be attributed to the fact that there are much more binding sites for AMP on the surface of bacteria than that for antibody. ${ }^{25}$ Thus, AMP-based bioassay can be employed for highly sensitive detection of $E$. coli $\mathrm{O} 157: \mathrm{H} 7$.

\subsection{Selectivity of the AMP-based bioassay}

To evaluate the specificity of the proposed bioassay, the responses of other bacteria, including $S$. Typhimurium, L. monocytogenes, $S$. aureus, $V$. parahaemolyticus and nonpathogenic E. coli DH5 $\alpha$ and BL21 at a higher concentration $\left(10^{6} \mathrm{cfu} \mathrm{mL}^{-1}\right)$ were investigated. As shown in Fig. 3B, the AMP-based assay showed only slight responses toward three species (L. monocytogenes, S. aureus, and $V$. parahaemolyticus). The responses of three Gram-negative species ( $S$. Typhimurium, E. coli DH5 $\alpha$ and BL21) were much higher than these of other three species, but the response of $E$. coli $\mathrm{O} 157: \mathrm{H} 7$ was the highest. These results are consistent with the previous research that magainin I exhibits selective activity toward some Gram-negative bacteria, especially $E$. coli $\mathrm{O} 157: \mathrm{H} 7 .^{13}$ For the Gram-negative species, the responses of $E$. coli DH5 $\alpha$ and BL21 were much smaller compared with that of $S$. Typhimurium. It was reported that the activity of AMPs toward bacteria is associated with many factors, such as the magnitude and location of LPS charge, outer membrane molecular architecture, and the presence or absence of the O-antigen side chain..$^{31}$ The difference in components and structure of the outer membrane of these Gram-negative species may lead to the different responses. The semi-selective binding property of AMPs implies the potential of the AMP-based assay in the detection of Gram-negative bacteria. However, the selectivity of the assay is needed to be improved when applied in the detection of a specific pathogen.

\subsection{Improvement of the selectivity for $E$. coli $0157: \mathrm{H} 7$}

Although the response of $E$. coli $\mathrm{O} 157: \mathrm{H} 7$ was highly sensitive, the responses of the other Gram-negative species cannot be ignored, especially $S$. Typhimurium. To improve the selectivity of the AMP-based bioassay toward E. coli O157:H7, a capturerelease procedure was introduced. The immunomagnetic beads-based capture-release procedure contains the selective capture of $E$. coli $\mathrm{O} 157: \mathrm{H} 7$ by immunomagnetic beads and the elution of the captured pathogens (Scheme 1 and S1 $\dagger$ ). Steric effects and non-specific binding between immunomagnetic beads and AMP are avoided in the capture-release procedure. Owing to the high efficiencies of capture and elution steps (97.9\% and $86.9 \%$, ESI $\dagger$ ), there were only slight influences on the sensitivity of the subsequent AMP-based assay. With the introduction of the capture-release procedure, the responses of different concentrations of E. coli $\mathrm{O} 157: \mathrm{H} 7$ were studied. As shown in Fig. $4 \mathrm{~A}$, the value of $\Delta \mathrm{OD}_{450}$ exhibited a good linear relationship with $E$. coli $\mathrm{O} 157: \mathrm{H} 7$ in the concentration range from 10 to $10^{5} \mathrm{cfu} \mathrm{mL}^{-1}$, which can be described by the 

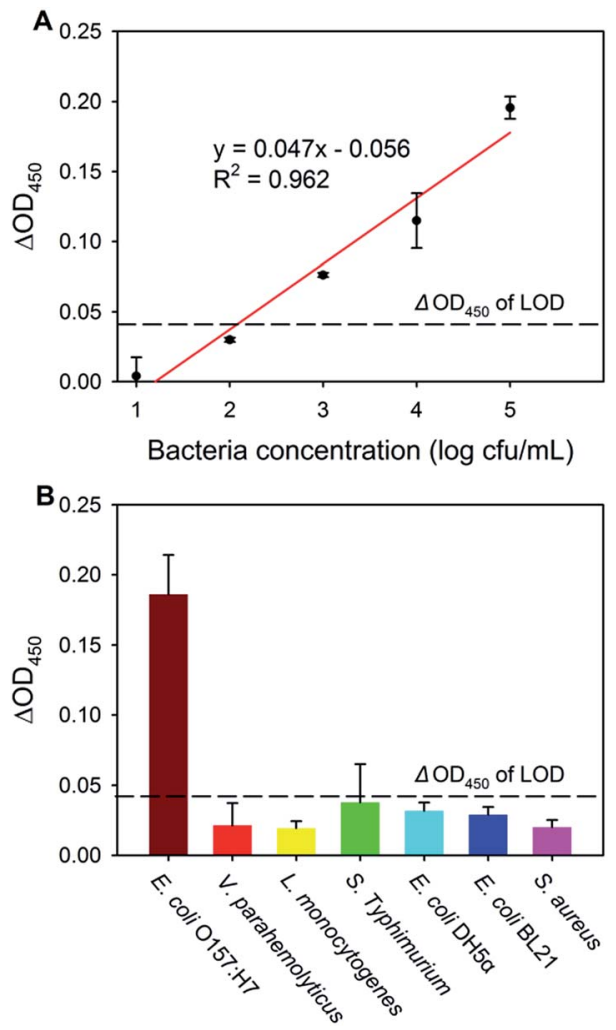

Fig. 4 (A) Detection of E. coli O157:H7 in pure culture by the AMPbased bioassay after the capture-release procedure. (B) The selectivity of the proposed AMP-based bioassay toward E. coli O157:H7 after the capture-release procedure. The concentrations of E. coli O157:H7 and

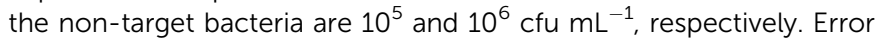
bars represent S.D. $(n=3)$.

equation $y=0.047 x-0.056\left(R^{2}=0.962\right)$, with a LOD of $118 \mathrm{cfu}$ $\mathrm{mL}^{-1}$, which is better than many other assays. ${ }^{32-34}$ Next, the selectivity of the AMP-based bioassay combined with the capture-release procedure was examined (Fig. 4B). The responses of other bacteria at a 10 -fold concentration were negligible comparing with that of $E$. coli $\mathrm{O} 157: \mathrm{H} 7$. The optical responses of non-target bacteria were slightly higher than that of the negative control, which might be caused by the nonspecific adsorption. In addition, the values of $\Delta \mathrm{OD}_{450}$ of the three Gram-negative species ( $S$. Typhimurium, E. coli DH5 $\alpha$ and BL21) were higher than these of the other three non-target bacteria, which can be attributed to the fact that the antibody used in the study reacts against many "O" and "K" serotypes of $E$. coli, and the selectivity can be further improved by choosing more specific antibodies. ${ }^{35}$ According to above results, none of the responses of non-target bacteria passed that of LOD $(118 \mathrm{cfu}$ $\mathrm{mL}^{-1}$ ) and have little effect on the sensitivity. Therefore, combined with the capture-release procedure, the detection of E. coli $\mathrm{O} 157: \mathrm{H} 7$ with high sensitivity and selectivity was achieved using the AMP-based bioassay.

\subsection{Applications to bacteria detection in food samples}

To validate the use of the proposed bioassay in practical application, E. coli $\mathrm{O} 157: \mathrm{H7}$ in two different types of food

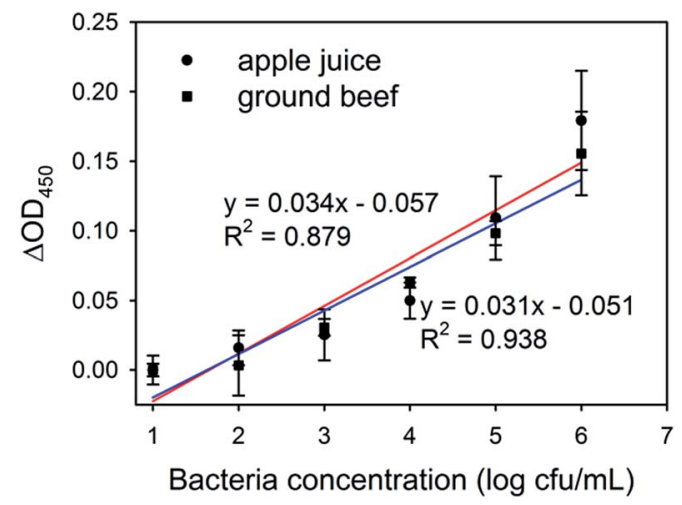

Fig. 5 Detection of E. coli O157:H7 in spiked apple juice and ground beef using the proposed AMP-based bioassay.

samples (apple juice and ground beef) was detected and the results are shown in Fig. 5. The optical signal increased gradually and presented a proportional relationship with the concentration of $E$. coli $\mathrm{O} 157: \mathrm{H} 7$, and the linear regression equations for apple juice and ground beef samples are $y=$ $0.034 x-0.057\left(R^{2}=0.879\right)$ and $y=0.031 x-0.051\left(R^{2}=0.938\right)$, respectively. The LOD were $119 \mathrm{cfu} \mathrm{mL}^{-1}$ in apple juice and 451 cfu $\mathrm{mL}^{-1}$ in ground beef. The LOD in apple juice was comparable to that of the pure culture samples while that of in ground beef was slightly high. This result might be caused by the complex components (especially fat) in ground beef, ${ }^{36}$ which interfered the binding of the antibody toward target bacteria, resulting in fewer target cells captured in immunomagnetic separation and consequently relative weaker optical signals in detection process. The results clearly indicated that the AMPbased bioassay could be employed to detect target bacteria in complex matrices.

\section{Conclusions}

In this study, the AMP-based assay was developed as a new approach for simple, rapid, and sensitive detection of $E$. coli O157:H7. AMP-HRP conjugates that can bind on the surface of bacteria rapidly with high density through the interaction with amphiphilic negatively charged LPS, were proved to be a more effective signal reporter than antibody. Combined with the capture-release procedure, the proposed bioassay could selectively detect $E$. coli $\mathrm{O} 157: \mathrm{H} 7$ as low as $118 \mathrm{cfu} \mathrm{mL}^{-1}$ in pure culture, as well as 119 and $451 \mathrm{cfu} \mathrm{mL}^{-1}$ in apple juice and ground beef in $45 \mathrm{~min}$, respectively. Furthermore, this AMPbased bioassay might be easily extended for the detection of other foodborne pathogens by choosing proper AMPs, exhibiting great promise in monitoring food safety.

\section{Acknowledgements}

This research was supported by the National Natural Science Foundation of China (Project No. 21505120) and the National Key Technology Research and Development Program of the Ministry of Science and Technology of China (Grant No. 
2013BAD19B02). The authors thank Dr Qinqin Hu for the help in revising the manuscript.

\section{References}

1 WHO (World Health Organization), Global burden of foodborne diseases, http://www.who.int/foodsafety/areas_work/foodbornediseases/ferg/en/, last updated 03.12.2015.

2 E. Scallan, P. M. Griffin, F. J. Angulo, R. V. Tauxe and R. M. Hoekstra, Emerging Infect. Dis., 2011, 17, 16-22.

3 N. L. Padola, Front. Microb., 2014, 5, 1-2.

4 S. D. Zumbrun, A. R. Melton-Celsa, M. A. Smith, J. J. Gilbreath, D. S. Merrell and A. D. O'Brien, Proc. Natl. Acad. Sci., India, Sect. B, 2013, 107, 2126-2133.

5 H. Vaisocherová-Lísalová, I. Víšová, M. L. Ermini, T. Špringer, X. C. Song, J. Mrázek, J. Lamačová, N. S. Lynn, P. Šedivák and J. Homola, Biosens. Bioelectron., 2016, 80, 84-90.

6 T. Jiang, Y. Song, T. Wei, H. Li, D. Du, M.-J. Zhu and Y. Lin, Biosens. Bioelectron., 2016, 77, 687-694.

7 P. Arora, A. Sindhu, H. Kaur, N. Dilbaghi and A. Chaudhury, Appl. Microbiol. Biotechnol., 2013, 97, 1829-1840.

8 A. G. Sciancalepore, E. Mele, V. Arcadio, F. Reddavide, F. Grieco, G. Spano, P. Lucas, G. Mita and D. Pisignano, Food Microbiol., 2013, 35, 10-14.

9 F. Dai, M. Zhang, B. Hu, Y. Sun, Q. Tang, M. Du and X. Zhang, RSC Adv., 2014, 5, 3574-3580.

10 R. L. Caygill, G. E. Blair and P. A. Millner, Anal. Chim. Acta, 2010, 681, 8-15.

11 C. Duarteguevara, V. V. Swaminathan, B. Reddy, J. C. Huang, Y. S. Liu and R. Bashir, RSC Adv., 2016, 6, 103872-103887.

12 J. Fei, W. Dou and G. Zhao, RSC Adv., 2015, 5, 74548-74556.

13 M. S. Mannoor, S. Zhang, A. J. Link and M. C. McAlpine, Proc. Natl. Acad. Sci., India, Sect. B, 2010, 107, 19207-19212.

14 E. K. Wujcik, H. Wei, X. Zhang, J. Guo, X. Yan, N. Sutrave, S. Wei and Z. Guo, RSC Adv., 2014, 4, 43725-43745.

15 S. Deshwal and E. B. Mallon, Dev. Comp. Immunol., 2014, 42, 240-243.

16 R. Hancock and A. Patrzykat, Curr. Drug Targets: Infect. Disord., 2002, 2, 79-83.
17 T. Rydlo, S. Rotem and A. Mor, Antimicrob. Agents Chemother., 2006, 50, 490-497.

18 R. Kanchanapally, B. P. Viraka Nellore, S. S. Sinha, F. Pedraza, S. J. Jones, A. Pramanik, S. R. Chavva, C. Tchounwou, Y. Shi and A. Vangara, RSC Adv., 2015, 5, 18881-18887.

19 H. Etayash, K. Jiang, T. Thundat and K. Kaur, Anal. Chem., 2014, 86, 1693-1700.

20 Y. Li, R. Afrasiabi, F. Fathi, N. Wang, C. Xiang, R. Love, Z. She and H.-B. Kraatz, Biosens. Bioelectron., 2014, 58, 193-199.

21 X. Liu, M. Marrakchi, D. Xu, H. Dong and S. Andreescu, Biosens. Bioelectron., 2016, 80, 9-16.

22 Z.-M. Dong and G.-C. Zhao, Talanta, 2015, 137, 55-61.

23 M. Zasloff, Nature, 2002, 415, 389-395.

24 E. T. Rietschel, T. Kirikae, F. U. Schade, U. Mamat, G. Schmidt, H. Loppnow, A. J. Ulmer, U. Zähringer, U. Seydel and F. Di Padova, FASEB J., 1994, 8, 217-225.

25 S. Arcidiacono, P. Pivarnik, C. M. Mello and A. Senecal, Biosens. Bioelectron., 2008, 23, 1721-1727.

26 A. G. Gehring and S.-I. Tu, Annu. Rev. Anal. Chem., 2011, 4, 151-172.

27 I. H. Cho, P. Bhandari, P. Patel and J. Irudayaraj, Biosens. Bioelectron., 2015, 64, 171-176.

28 M.-S. Chang, J. H. Yoo, D. H. Woo and M.-S. Chun, Analyst, 2015, 140, 7997-8006.

29 J. H. Yoo, D. H. Woo, M.-S. Chang and M.-S. Chun, Sens. Actuators, B, 2014, 191, 211-218.

30 A. G. González and M. Á. Herrador, TrAC, Trends Anal. Chem., 2007, 26, 227-238.

31 F. R. Rana, E. A. Macias, C. M. Sultany, M. C. Modzrakowski and J. Blazyk, Biochemica, 1991, 30, 5858-5866.

32 Y. Chen and M. Xie, RSC Adv., 2015, 5, 100633-100637.

33 J. Wen, Sci. Rep., 2014, 4, 2253.

34 H. S. Kim, Y. J. Kim, J. W. Chon, D. H. Kim, J. H. Yim, H. Kim and K. H. Seo, Sens. Actuators, B, 2017, 239, 94-99.

35 M. Xu, R. Wang and Y. Li, Analyst, 2016, 141, 5441-5449.

36 M. Varshney, L. Yang, X. L. Su and Y. Li, J. Food Prot., 2005, 68, 1804-1811. 